\title{
Trick or treat: A field study of social class differences in altruism
}

\author{
GLENN E. LITTLEPAGE and HAROLD D. WHITESIDE \\ Middle Tennessee State University, Murfreesboro, Tennessee 37132
}

\begin{abstract}
Previous research has demonstrated social class differences in altruism; specifically, middle-class members are more sensitive to reciprocity norms than lower-class members. The present study investigated social class differences in altruism in a situation in which reciprocity norms were not particularly salient. Children trick or treated and received candy from 63 houses representing upper-, middle-, and lower-middle-class neighborhoods. Candy from each house was rated for subjective quality; results revealed that quality of candy was not related to social class. Contrary to studies of altruism in other settings, the relative cost of giving had no effect. This suggests that cost factors may not be related to altruism in all conditions.
\end{abstract}

Recent evidence suggests that altruistic behavior is less likely if the costs of helping are high. Sechrest and Flores (1974) have noted that the extent to which prison inmates shared cigarettes with other prisoners was a function of the number of cigarettes available. This suggests that the quantity of a commodity might influence a person's generosity with respect to that commodity. Therefore, persons of a higher social class, being more affluent, might be expected to be more generous in situations involving financial altruism than members of lower classes. While Rosenhan (cited in Sechrest \& Flores, 1974) found no social class differences in contributions to charity, a survey by the Commission on Foundations and Private Philanthropy (1970) suggests that the wealthy do contribute more per capita. Nevertheless, the motivational base for such donations has not been specified and the generality has not been demonstrated. The present study attempts to shed some light on these issues by examining social class differences in altruism in a naturally occurring context.

Although previous research has shown that social class affects altruistic behavior (Berkowitz \& Friedman, 1967; Dreman \& Greenbaum, 1973), these effects have been demonstrated only for altruistic behavior motivated by reciprocity norms. If, as Sechrest and Flores (1974) suggest, those with a greater surplus are more willing to share, then social class should be positively related to altruistic behavior, even in situations in which the reciprocity norm is not salient.

The present study was designed to investigate altruistic behavior in such a situation. Halloween provided an appropriate setting. Most trick or treaters are not

The authors are grateful to Jeff Haynes, Cindy Ingram, Linda Haley, and Nick Littlepage for their assistance. Address reprint requests to Glenn Littlepage, Psychology Department, Middle Tennessee State University, Murfreesboro, Tennessee 37132. This paper is sponsored by Robert E. Prytula, who takes full editorial responsibility for its contents. identifiable to the donors, and many households do not have children who solicit candy from others. Thus, reciprocity norms or notions of exchange should not be particularly salient.

\section{METHOD}

\section{Subjects}

Subjects consisted of residents of selected areas of a relatively small community (population about 30,000 ). Only residents who opened their doors and provided candy to "trick or treaters" were included.

\section{Procedure}

Nine areas of town were selected to represent three distinct economic categories. Three areas consisted of mostly twobedroom frame houses, selected to represent lower-middle-class dwellings. Three other areas, consisting primarily of threebedroom brick houses, were designated as middle-class dwellings; and three additional areas, containing mostly spacious brick dwellings in prestigious areas, were selected to represent the upper class.

The study involved children trick or treating at houses in the selected areas. Three children between the ages of 6 and 9 years served as data collectors. Each received candy from seven houses in each area; each trick or treated in three areas, one from each social class. They all began trick or treating around 5:00 p.m. and concluded about 8:00 p.m.; data collection was arranged so that social class was counterbalanced with time of night. The candy received from each house was collected and identified. Following data collection, the children were paid and were given candy to replace the study candy. The study candy was rated for quality by 13 college students, using a 7-point scale ranging from "terrible-the child would be very disappointed with this candy" (coded 1) to "excellent-the child would be very pleased with this candy" (coded 7).

\section{RESULTS}

The ratings showed considerable variability, but were positively correlated (mean $\mathrm{r}=+.57$ ). Ratings of the candy collected from each house were used as an index of the quality of the candy and served as data. These data were analyzed using a 3 by 3 by 13 analysis of 
Table 1

Mean Candy Ratings by Social Class and Time of Night

\begin{tabular}{cccc}
\hline $\begin{array}{c}\text { Approximate } \\
\text { Time }\end{array}$ & $\begin{array}{c}\text { Lower-Middle } \\
\text { Class }\end{array}$ & $\begin{array}{c}\text { Middle } \\
\text { Class }\end{array}$ & $\begin{array}{c}\text { Upper } \\
\text { Class }\end{array}$ \\
\hline 5:00-6:00 & 3.46 & 3.76 & 3.99 \\
6:00-7:00 & 3.90 & 3.95 & 4.05 \\
7:00-8:00 & 4.12 & 3.28 & 3.88 \\
\hline
\end{tabular}

variance design, with repeated measures on the last factor to assess the effects of Social Class, Time of Night, and Rater, respectively. This analysis revealed that neither Social Class, Time of Night, nor their interaction significantly influenced the quality of candy given to trick or treaters, but that the Raters differed in their overall evaluation of the candy, $F(13,634)=53.36$, $\mathrm{p}<.001$. Ratings for the candy collected in the nine areas are presented in Table 1 .

\section{DISCUSSION}

These results, contrary to the hypothesis, suggest that Halloween giving is not related to social class. Apparently, the social norms which influenced this traditional form of altruism are followed equally closely regardless of social class.

These findings are inconsistent with Sechrest and Flores' (1974) results showing that a large surplus leads to more altruism. It is not entirely clear why helping was related to size of surplus in their study but not in the present one. However, there are several differences between these two studies. First, in their study, subjects were prisoners and may have felt some pressures toward group solidarity. Similarly, because many prisoners may not have had access to cigarettes, other prisoners may have perceived them to be in need. Also, it is possible that, although Sechrest and Flores (1974) tried to eliminate threat, it was perceived by the prisoners. It is unlikely that subjects in the present study felt great solidarity with the trick or treaters, perceived a threat, or felt the children were in great need. In addition, Sechrest and Flores' (1974) subjects received a commodity and were immediately asked to respond altruistically with the same commodity; thus, the surplus was very salient to the request. Perhaps a trick-or-treat request does not cause residents to pay much attention to their own income level, and thus their ability to buy candy. Finally, Halloween candy may represent such a small portion of income that it represents a minimal cost to even the poorest subjects in this study.

Thus, there are many differences between this study and the Sechrest and Flores (1974) study that may have accounted for the differing results. Although it is not possible to pinpoint the critical differences, it is apparent that cost factors are not related to altruism in all situations. Further research is needed to document the relationship between a surplus and altruism and to specify the conditions under which the relationship holds.

\section{REFERENCES}

Berkowitz, L., \& Friedman, P. Some social class differences in helping behavior. Journal of Personality and Social Psychology, 1967, 5, 217-225.

Commission on Foundations and Private Philanthropy. Foundations, private giving, and public policy. Chicago: University of Chicago Press, 1970.

Dreman, S. D., \& Greenbaum, D. Altruism and reciprocity: Sharing behavior in Israeli kindergarten children. Child Development, 1973, 44, 61-68.

Sechrest, L., \& Flores, L. Surplus and sharing in a prison sample. Journal of Social Psychology, 1974, 94, 33-44.

(Received for publication March 21, 1976.) 